\title{
Type 1 diabetes in adults: supporting self management
}

\author{
Monika Reddy specialist registrar, diabetes and endocrinology ${ }^{12}$, Sian Rilstone diabetes specialist \\ dietitian $^{2}$, Philippa Cooper has type 1 diabetes $^{3}$, Nick S Oliver consultant diabetologist ${ }^{12}$
}

'Department of Diabetes, Endocrinology and Metabolism, Imperial College London, St Mary's Hospital Campus, London W2 1PG, UK; ${ }^{2}$ Diabetes and Endocrinology, Imperial Healthcare NHS Trust, London; ${ }^{3}$ London

Type 1 diabetes affects 300000 people in the United Kingdom. ${ }^{12}$ Despite regular specialist multidisciplinary input, responsibility for glucose monitoring and insulin administration is devolved to the person with diabetes, or their care giver. Empowering effective self management of type 1 diabetes is critical to achieve $\mathrm{HbA}_{1 \mathrm{c}}$ targets, minimise hypoglycaemia and optimise quality of life. Structured education programmes for diabetes self management should be offered to everyone with type 1 diabetes. It is important for healthcare providers to understand what structured education involves before referral. This review examines the meaning and evidence for self management, and provides advice on how general physicians and non-specialists can support and enable people with type 1 diabetes to self manage their condition.

\section{What is required for self management of type 1 diabetes?}

Insulin requirements and glucose concentrations are affected by multiple internal and external factors (see box 1), and maintaining glycaemic control while minimising hypoglycaemia with a flexible daily routine is a challenge. The benefit of intensive glucose control in reducing long term complications in type 1 diabetes is well established, based on the Diabetes Control and Complications Trial (DCCT). ${ }^{3}$ However, this was at the expense of an increase in severe hypoglycaemia (61.2 per 100 patient years in the intensive control group compared with 18.7 in the control group). ${ }^{4}$ Newer analogue insulins and modern insulin pumps have enabled $\mathrm{HbA}_{1 \mathrm{c}}$ reduction with an associated reduction in the frequency and severity of hypoglycaemia. ${ }^{56}$ Self management remains challenging, and $73 \%$ of people with type 1 diabetes do not achieve an $\mathrm{HbA}_{1 \mathrm{c}}$ target of $<58 \mathrm{mmol} / \mathrm{mol}$ $(7.5 \%){ }^{1}$

\section{What is a structured education programme for type 1 diabetes?}

A structured education programme for type 1 diabetes is defined as "a planned and graded process that facilitates the knowledge, skills and ability for diabetes self management and empowers individuals to live healthily, to maintain and improve their quality of life, and assume an active role in their diabetes care team." Structured education programmes are required to be evidence based, theory driven, quality assured, audited regularly, and have a formal written curriculum delivered by trained educators. ${ }^{7}$

It includes education on self monitoring of blood glucose (SMBG), carbohydrate counting, and insulin dose adjustment at mealtimes ${ }^{89}$ to achieve optimal glycaemic control and quality of life. Examples of structured education programmes are the Dose Adjustment for Normal Eating (DAFNE) course ${ }^{9}$ (adapted from a German programme) and PRIMAS (Programme for diabetes education and treatment for a self determined living with type 1 diabetes). ${ }^{10}$ Box 2 summarises the principles and syllabus content of structured education.

\section{Do structured education programmes for type 1 diabetes work?}

In a multicentre randomised controlled trial, DAFNE reduced $\mathrm{HbA}_{1 \mathrm{c}}$ and improved quality of life 12 months after completion. ${ }^{9}$ Further follow-up at four years showed that the psychosocial benefit was sustained. ${ }^{8}$ A meta-analysis of 15 randomised controlled trials of structured education for type 1 diabetes $^{9-24}$ suggested no overall impact on $\mathrm{HbA}_{1 \mathrm{c}}$ at either six or 12 months' follow-up. However, DAFNE ${ }^{9}$ and PRIMAS ${ }^{10}$ were the exceptions to this, with DAFNE showing a reduction in $\mathrm{HbA}_{1 \mathrm{c}}$ of $1 \%$ (95\% confidence interval $0.58 \%$ to $1.42 \%)$ and PRIMAS achieved a reduction of $0.4 \%(0.15 \%$ to $0.65 \%)$ from baseline to six months.

\section{Who should receive a structured education programme?}

All adults with type 1 diabetes should be offered an evidence based, structured education programme, and have its benefits explained, after 6-12 months of diagnosis. ${ }^{7}$ The delay from diagnosis to education allows people time to adjust to their diagnosis and to be established on an insulin regimen beyond the initial honeymoon phase, which is characterised by partial recovery of endogenous insulin secretion. If a person is unable 


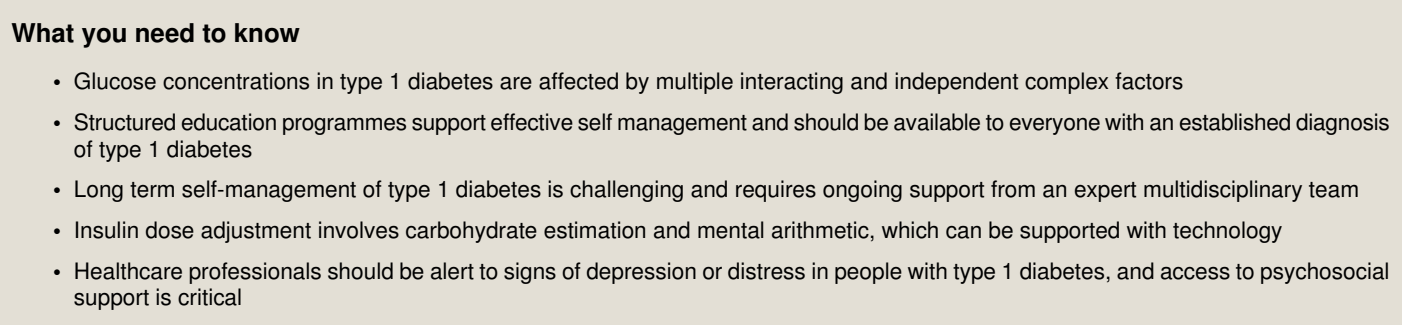

\section{Sources and selection criteria}

A PubMed search using the terms "self management in type 1 diabetes" and "structured education in type 1 diabetes" was performed. The clinical evidence base included in the NICE guidelines on diagnosis and management of type 1 diabetes (NG17 2015) was reviewed. The reference list included in this review is not exhaustive, but includes the most relevant up to date studies.

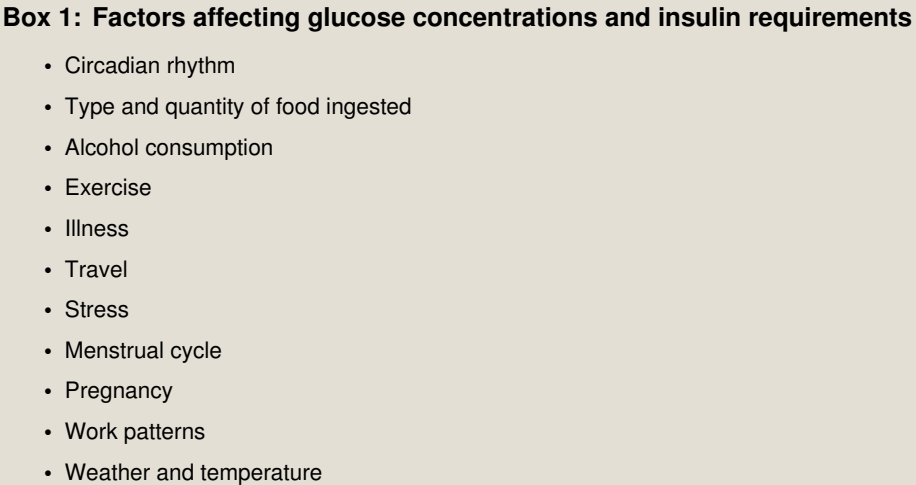

\section{Box 2: Structured education principles and content}

- Structured education programmes should be evidence based, quality assured, and delivered by trained educators (diabetes specialist nurses, dieticians, diabetologists)

- Generic components of structured education programmes must include:

- Self monitoring of blood glucose and ketones

- Dietary advice, including alcohol

- Carbohydrate counting

- Physical activity

- Prevention and managing hypoglycaemia

- Psychological support

- Peer support

- Driving

or unwilling to participate in group education, an alternative education method of equal standard should be provided, such as one-to-one education sessions with a diabetes specialist dietitian and nurse. In addition, Blood Glucose Awareness Training (BGAT), a separate psychoeducational intervention designed to improve recognition and interpretation of relevant symptoms, should be considered for people with recurrent hypoglycaemia. ${ }^{20}$

\section{Supporting self management in primary care}

Type 1 diabetes is ideally managed by the person with type 1 diabetes, with support from a multidisciplinary team including primary and specialist care. The components of structured education are outlined below with an evidence based summary for each section.

\section{Self monitoring of blood glucose and ketones}

Self monitoring of blood glucose guides changes to insulin treatment and is a core component of self management of type 1 diabetes. Observational studies show that such self monitoring is associated with reduced $\mathrm{HbA}_{1 \mathrm{c}}{ }^{25-27} \mathrm{~A}$ cost effectiveness analysis carried out by the National Institute for Health and Care Excellence (NICE), based on four randomised controlled trials and 31 observational studies, found that self monitoring of blood glucose 8-10 times a day was the most cost effective strategy to optimise glucose levels. ${ }^{7}$ Only one of these studies, a cross sectional study with 8914 participants, included a frequency of self monitoring of blood glucose of more than 10 per day. ${ }^{28}$ There is limited evidence to suggest the best timing of blood glucose measurements throughout the day ${ }^{29}$ or to provide optimal blood glucose targets. One small observational study $(n=31)$ reported that nocturnal hypoglycaemia is unlikely to have 
occurred if blood glucose was $>5.5 \mathrm{mmol} / \mathrm{L}$ on waking. ${ }^{30}$ Another observational study established blood glucose targets to achieve specific $\mathrm{HbA}_{1 \mathrm{c}}$ goals. To achieve an $\mathrm{HbA}_{1 \mathrm{c}}$ of 6.5-6.99\% (48-53 $\mathrm{mmol} / \mathrm{mol})$, the mean fasting blood glucose concentration was $144 \mathrm{mg} / \mathrm{dL}(8 \mathrm{mmol} / \mathrm{L})$ and mean pre-prandial glucose level was $140 \mathrm{mg} / \mathrm{dL}(7.8 \mathrm{mmol} / \mathrm{L}){ }^{27}$ The NICE recommendations ${ }^{4}$ on frequency of self monitoring of blood glucose and targets are listed in box 3 .

When choosing a glucose meter it is important to take into account the needs of the individual user (such as option to measure ketones, incorporated bolus calculator, compatibility with web based software for data upload, ease of use, practicality), but also to ensure that International Organisation for Standardization (ISO) standards are met. ${ }^{31}$ Self monitoring of either urine or blood ${ }^{32}$ ketones should be considered to facilitate self management of hyperglycaemia, especially during illness, to prevent development of diabetic ketoacidosis ${ }^{33}$ and for guidance on when to seek medical help.

\section{Are there recommended diets for type 1 diabetes?}

People with newly diagnosed type 1 diabetes should be offered a dietetic review with a type 1 diabetes specialist dietitian for nutritional information to discuss a dietary management plan. Dietitians should continue to be available after diagnosis, either as part of a group education programme or on a one-to-one basis to teach people to count carbohydrates and to support personal eating choices. Individuals should be able to adopt a balanced diet to promote good overall health, manage glycaemia, and maintain a healthy weight, blood pressure, and blood lipids in line with evidence based guidelines. ${ }^{7-36}$ The amount of carbohydrate and available insulin are the most important factors influencing glycaemic control in people with type 1 diabetes. ${ }^{34}$ The evidence is inconclusive as to what the ideal total carbohydrate intake is in people with diabetes. ${ }^{7-36}$ The advice for the general population is that $50 \%$ of energy should come from carbohydrate, ${ }^{37}$ but a healthy diet can contain a range of energy from carbohydrate, and this is greatly influenced by the source of carbohydrate and general balance of the diet. People with type 1 diabetes should be enabled to follow a healthy, balanced, cardioprotective diet with meal sizes appropriate to their weight. The most important feature is that carbohydrate intake and insulin doses should be matched. ${ }^{35}$

Adults with type 1 diabetes should not routinely be advised to follow a low glycaemic index diet. ${ }^{38}$ A prospective randomised controlled trial found no clinical benefit of a low glycaemic index diet versus a high glycaemic index diet. Multiple anecdotal and observational reports support other diets in type 1 diabetes, including low carbohydrate diets. However, there are no randomised controlled trials to support these diets, and people with type 1 diabetes should have access to a specialist dietitian to discuss the risks and benefits of diets-with support, where appropriate, to safely, and effectively self manage their diabetes.

\section{How are meal insulin boluses adjusted?}

Mealtime insulin bolus doses are estimated according to the carbohydrate content of the food ingested and current blood glucose. Structured education includes training in "carbohydrate counting," which estimates the amount of carbohydrate (in grams) contained in a meal. Carbohydrate counting has been shown to improve overall glycaemic control in randomised controlled trials. ${ }^{39-41}$ Structured education also teaches how to estimate individualised insulin:carbohydrate ratios (the amount of carbohydrate (grams) covered by 1 unit of insulin) and an insulin sensitivity factor (ISF, the reduction in blood glucose by 1 unit of insulin). The insulin bolus for each meal can be calculated using a simple formula, taking into account the target glucose, current glucose, carbohydrate content of meal (grams), insulin:carbohydrate ratio, and ISF (example given in box 4). Bolus calculators are incorporated into most insulin pumps and also into some capillary blood glucose metres for multiple dose insulin injection users. Randomised controlled trials have shown that bolus calculators can improve glucose $\operatorname{control}^{42}{ }^{43}$ but require regular review of the fixed insulin:carbohydrate ratios and ISF parameters by the patient, as these parameters may change over time or in certain circumstances (such as after exercise and during intercurrent illness) due to factors such as weight, stress, medication, hormonal changes, exercise, weather and work.

It is important to empower people with type 1 diabetes to count carbohydrate content but also to understand the impact of differing carbohydrates, fats, and proteins on their glucose concentrations and insulin requirements. Starches and sugars may be digested at different rates depending on natural structure and degree of processing, and a high fat or protein content may delay carbohydrate absorption and decrease insulin sensitivity. ${ }^{44}$

\section{What should patients do about exercise?}

If there are no contraindications to exercise, people with type 1 diabetes should be encouraged to exercise regularly to reduce medium to long term cardiovascular risk. ${ }^{45}$ Box 5 provides general advice on nutritional support, blood glucose monitoring, and insulin dose adjustment before, during, and after exercise. Managing insulin requirements before, during, and after exercise is particularly important as exercise promotes glucose uptake in skeletal muscle independently of insulin and increases peripheral insulin sensitivity, increasing the risk of hypoglycaemia, both during exercise and for several hours afterwards. ${ }^{46}$ Blood glucose management during exercise can be challenging, and different exercises can have different impacts on glucose, with hyperglycaemia commonly seen after anaerobic or competitive exercise, and hypoglycaemia after moderate aerobic work.

\section{How to manage hypoglycaemia}

People with diabetes should be made aware of the symptoms of hypoglycaemia, which may include hunger, irritability, anxiety, sweating, and palpitations. As the glucose concentration falls further, cognitive impairment with confusion may occur, but this varies from person to person and may change over time. Treatment for impending hypoglycaemia is recommended at a threshold of $4 \mathrm{mmol} / \mathrm{L}$, though international definitions of hypoglycaemia vary. Recognising symptoms of hypoglycaemia and promptly self treating are crucial, as severe hypoglycaemia (defined as requiring the assistance of another person to treat) or prolonged hypoglycaemia is distressing and can result in seizures, cardiac arrhythmias, and death.$^{47}$ The commonest recommendation for self treatment of biochemical or symptomatic hypoglycaemia is $15 \mathrm{~g}$ of fast acting carbohydrate (such as dextrose tablets, a sugary drink, or, in the UK, Bassett's Jelly Babies (as they are almost exactly $5 \mathrm{~g}$ of carbohydrate per "baby")). ${ }^{7}$ However, a recent randomised controlled crossover study suggested that weight based treatment of hypoglycaemia using $0.3 \mathrm{~g} / \mathrm{kg}$ glucose is more effective in resolving hypoglycaemia than a standard $15 \mathrm{~g} .^{48}$ 


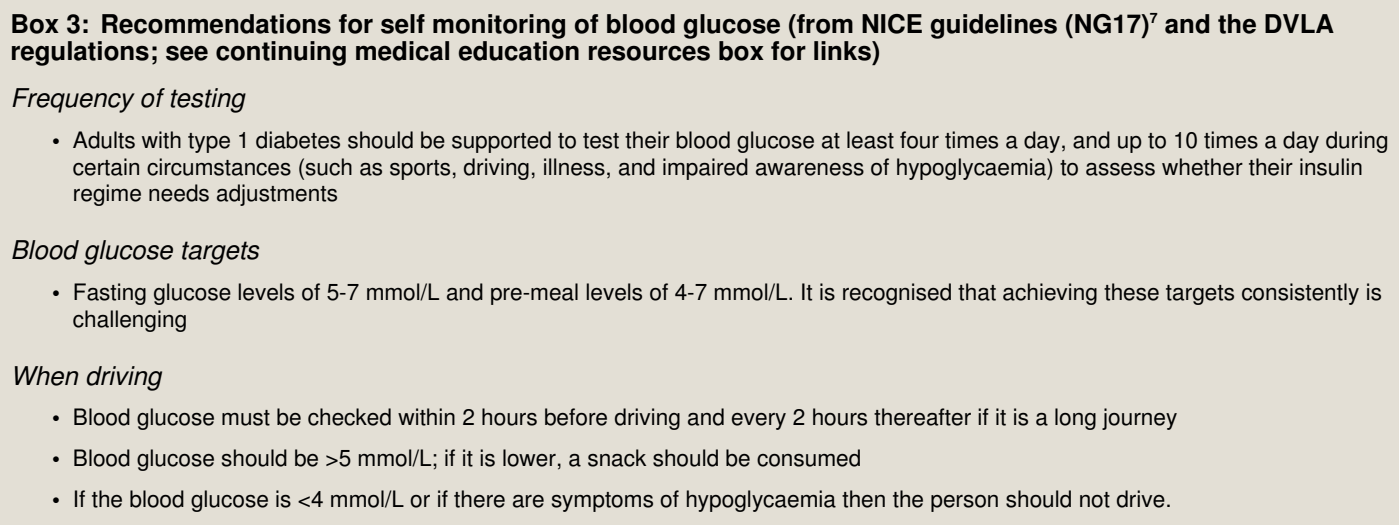

Box 4: Insulin bolus estimation using carbohydrate counting and self-testing of blood glucose

Equation used for meal bolus estimation

$(\mathrm{CHO} \div \mathrm{ICR})+\left(\left(\mathrm{G}-\mathrm{G}_{\mathrm{T}}\right) \div \mathrm{ISF}\right)=$ insulin bolus dose

where

$\mathrm{CHO}=$ carbohydrate content of meal (in grams) (Carbs\&Cals (www.carbsandcals.com) provides guidance on carbohydrate estimation) ICR = insulin:carbohydrate ratio (the amount of insulin required for a fixed amount of carbohydrate, usually expressed as units per 10 grams of carbohydrate)

$\mathrm{G}=$ Capillary blood glucose

$\mathrm{G}_{\mathrm{T}}=$ Capillary blood glucose target

ISF = Insulin sensitivity factor (the glucose decrease for 1 unit of insulin given)

Example of a meal bolus calculation

For a breakfast meal consisting of $40 \mathrm{~g}$ of carbohydrate and pre-breakfast capillary blood glucose of $10 \mathrm{mmol} / \mathrm{L}$ :

Carbohydrate content $(\mathrm{CHO})$ of a bowl of cereal with milk $=40 \mathrm{~g}$

Capillary blood glucose $(\mathrm{G})$ measured just before breakfast $=10 \mathrm{mmol} / \mathrm{L}$

Examples of individualised parameters used:

Glucose target $(\mathrm{GT})=6 \mathrm{mmol} / \mathrm{L}$

Insulin:carbohydrate ratio (ICR) $=10 \mathrm{~g}$ ( 1 unit of insulin for every $10 \mathrm{~g}$ of carbohydrate)

Insulin sensitivity factor (ISF) $=2$ ( 1 unit of insulin to bring down the blood glucose by $2 \mathrm{mmol} / \mathrm{L}$ )

Bolus calculation for the breakfast meal using the information outlined above

Insulin bolus dose $=(40 \div 10)+((10-6) \div 2)=6$ units

Box 5: Points to consider before and during exercise (adapted from www.runsweet.com)

- Ensure safe levels of pre-exercise blood glucose (such as 7-12 mmol/L)

- Consider ingesting extra carbohydrates if blood glucose is $<7 \mathrm{mmol} / \mathrm{L}$ before exercise

- Measure blood-glucose before, during, and after exercise

- Consider reduction in insulin dose by at least $20 \%$, possibly with additional quick acting carbohydrates to be consumed during moderate intensity endurance exercise (general guide, $1 \mathrm{~g} / \mathrm{kg} / \mathrm{hour}$ )

\section{Impaired hypoglycaemia awareness}

Recurrent hypoglycaemia can lead to a reduction in a person's ability to recognise symptoms of hypoglycaemia (impaired hypoglycaemia awareness). ${ }^{49}{ }^{50}$ Annual specialist review includes assessment of hypoglycaemia awareness using the Gold or Clarke score (box 6). If this is impaired, options include additional education focused on hypoglycaemia avoidance ${ }^{11-14}$ without relaxing glucose targets, or continuous subcutaneous insulin infusion therapy. Hypoglycaemia and fear of hypoglycaemia can affect the quality of life of people with type 1 diabetes and their families. ${ }^{53}$ Specialist care is important to manage recurrent or severe hypoglycaemia to reduce cost, morbidity, and mortality and improve quality of life.

\section{Psychological support}

Demands of frequent self monitoring of blood glucose, insulin injections, lifestyle changes, disturbed sleep, and worry about hypoglycaemia and other complications can cause emotional stress. This can affect glycaemic control, relationships with family and friends, and psychological wellbeing. Emotional stress can also result from interactions with doctors who do not acknowledge their limitations on type 1 diabetes management and, as a result, unintentionally create a barrier to empowering self management and give unrealistic expectations. ${ }^{54}$ Data derived from a meta-analysis showed a statistically significantly higher prevalence of depression among people with type 1 diabetes compared with the non-diabetic population $(21.7 \% \mathrm{v}$ $8.6 \%, \mathrm{P}<0.001) .{ }^{55}$ Healthcare professionals supporting type 1 diabetes self management must be alert to early signs of depression and anxiety, in particular in those who find the challenges of self management distressing.

A referral to a specialist diabetes psychologist should be considered if a person has diabetes related distress or persistent psychological barriers to effective glycaemic management. 


\section{Box 6: Calculation of Gold or Clarke score for assessment of hypoglycaemia awareness}

Gold score - Based on the response to a single question: "Do you know when your 'hypos' are commencing?" Results are derived from a 7-point Likert scale, where 1 is "always aware" and 7 is "never aware"51

Clarke score-Made up of eight questions characterising exposure to episodes of moderate and severe hypoglycaemia to assess the glycaemic threshold for and symptomatic response to hypoglycaemia. ${ }^{52}$

A value of $\geq 4$ in both scoring systems suggests impaired hypoglycaemia awareness

\section{How does a multidisciplinary diabetes team support effective self management?}

The specialist multidisciplinary team should comprise specialists with relevant complementary skills who work with a person with type 1 diabetes either together or in close communication with each other (see box 7). The team should be encouraged to work and communicate efficiently while providing advice that is consistent with the evidence base and best practice.

Competing interest: We have read and understood BMJ policy on declaration of interests and have no relevant interests to declare. Provenance and peer review: Commissioned; externally peer reviewed.

Group TNA. National Diabetes Audit 2012-2013 Report 1: Care processes and treatment targets. Health and Social Care Information Centre, 2014: 28.

2 Gadsby R, Young B. Diabetes care in England and Wales: information from the 2010-2011 National Diabetes Audit. Diabet Med 2013;30:799-802. doi:10.1111/dme.12182. 23551249. The Diabetes Control and Complications Trial Research Group. The effect of intensive treatment of diabetes on the development and progression of long-term complications in insulin-dependent diabetes mellitus. N Engl J Med 1993;329:977-86. doi:10.1056/ NEJM199309303291401. 8366922

4 The Diabetes Control and Complications Trial Research Group. Hypoglycemia in the Diabetes Control and Complications Trial. Diabetes 1997;46:271-86. doi:10.2337/diab. 46.2.271. 9000705

5 Pickup JC. Management of diabetes mellitus: is the pump mightier than the pen? Nat Rev Endocrinol 2012;8:425-33. doi:10.1038/nrendo.2012.28. 22371161.

6 Monami M, Marchionni N, Mannucci E. Long-acting insulin analogues vs. NPH human insulin in type 1 diabetes. A meta-analysis. Diabetes Obes Metab 2009:11:372-8 doi:10. 1111/j.1463-1326.2008.00976.x. 19267715.

7 National Institute for Health and Care Excellence. Type 1 diabetes in adults: diagnosis and management. (NICE guidance 17.) 2015:612. www.nice.org.uk/guidance/ng17.

8 Speight J, Amiel S, Bradley C, et alThe Dose Adjustment For Normal Eating (DAFNE) Trial: improvements in $\mathrm{HbA1c}$ still apparent and quality of life benefits well maintained at 4-year follow-up. Diabet Med 2007:24(suppl 1):95, P224.

9 DAFNE Study Group. Training in flexible, intensive insulin management to enable dietary freedom in people with type 1 diabetes: dose adjustment for normal eating (DAFNE) randomised controlled trial. BMJ 2002;325:746. doi:10.1136/bmj.325.7367.746. 12364302

10 Hermanns N, Kulzer B, Ehrmann D, Bergis-Jurgan N, Haak T. The effect of a diabetes education programme (PRIMAS) for people with type 1 diabetes: results of a randomized trial. Diabetes Res Clin Pract 2013;102:149-57. doi:10.1016/..diabres.2013.10. 009. 24210673.

11 Cox DJ, Kovatchev B, Koev D, et al. Hypoglycemia anticipation, awareness and treatmen training (HAATT) reduces occurrence of severe hypoglycemia among adults with type diabetes mellitus. Int J Behav Med 2004;11:212-8. doi:10.1207/s15327558ijbm1104 4. 15657021.

12 de Weerdt I, Visser AP, Kok GJ, de Weerdt O, van der Veen EA. Randomized controlled multicentre evaluation of an education programme for insulin-treated diabetic patients: effects on metabolic control, quality of life, and costs of therapy. Diabet Med 1991;8:338-45. doi:10.1111/j.1464-5491.1991.tb01607.x. 1830257.

13 George JT, Valdovinos AP, Russell I, et al. Clinical effectiveness of a brief educationa intervention in Type 1 diabetes: results from the BITES (Brief Intervention in Type 1 diabetes, Education for Self-efficacy) trial. Diabet Med 2008:25:1447-53. doi:10.1111/j. 1464-5491.2008.02607.x. 19046244.

14 Hermanns N, Kulzer B, Kubiak T, Krichbaum M, Haak T. The effect of an education programme (HyPOS) to treat hypoglycaemia problems in patients with type 1 diabetes. Diabetes Metab Res Rev 2007;23:528-38. doi:10.1002/dmrr.710. 17245692.

15 Korhonen T, Huttunen JK, Aro A, et al. A controlled trial on the effects of patient education in the treatment of insulin-dependent diabetes. Diabetes Care 1983:6:256-61. doi:10. 2337/diacare.6.3256. 6347578

16 Lennon GM, Taylor KG, Debney L, Bailey CJ. Knowledge, attitudes, technical competence, and blood glucose control of Type 1 diabetic patients during and after an education programme. Diabet Med 1990;7:825-32. doi:10.1111/j.1464-5491.1990.tb01500. x. 2148137.

17 Rossi MC, Nicolucci A, Pellegrini F, et al. Interactive diary for diabetes: A useful and easy-to-use new telemedicine system to support the decision-making process in type 1 diabetes. Diabetes Technol Ther 2009:11:19-24 doi:10.1089/dia.2008.0020. 19132851.

18 Rossi MC, Nicolucci A, Di Bartolo P, et al. Diabetes Interactive Diary: a new telemedicine system enabling flexible diet and insulin therapy while improving quality of life: an open-label, international, multicenter, randomized study. Diabetes Care 2010;33:109-15. doi:10.2337/dc09-1327. 19808926 .

19 Rossi MC, Nicolucci A, Lucisano G, et al. Did Study Group. Impact of the "Diabetes Interactive Diary" telemedicine system on metabolic control, risk of hypoglycemia, and quality of life: a randomized clinical trial in type 1 diabetes. Diabetes Technol Ther 2013;15:670-9. doi:10.1089/dia.2013.0021. 23844569.
20 Schachinger $\mathrm{H}$, Hegar K, Hermanns N, et al. Randomized controlled clinical trial of Blood Glucose Awareness Training (BGAT III) in Switzerland and Germany. J Behav Med 2005:28:587-94. doi:10.1007/s10865-005-9026-3. 16222412.

21 Snoek FJ, van der Ven NC, Twisk JW, et al. Cognitive behavioural therapy (CBT) compared with blood glucose awareness training (BGAT) in poorly controlled Type 1 diabetic patients: long-term effects on $\mathrm{HbA}$ moderated by depression. A randomized controlled trial. Diabe Med 2008;25:1337-42.19046225.

22 Terént A, Hagfall $\mathrm{O}$, Cederholm $\mathrm{U}$. The effect of education and self-monitoring of blood glucose on glycosylated hemoglobin in type I diabetes. A controlled 18-month trial in a representative population. Acta Med Scand 1985:217:47-53 doi:10.1111/j.0954-6820. 1985.tb01633.x. 3883704.

23 Trento M, Passera P, Borgo E, et al. A 3-year prospective randomized controlled clinical trial of group care in type 1 diabetes. Nutr Metab Cardiovasc Dis 2005;15:293-301. doi: 10.1016/..numecd.2004.12.005. 16054554.

24 Trento M, Trinetta A, Kucich C, et al. Carbohydrate counting improves coping ability and metabolic control in patients with Type 1 diabetes managed by Group Care. J Endocrinol Invest 2011;34:101-5. doi:10.1007/BF03347038. 20440106.

25 Kovatchev BP, Cox DJ, Straume M, Farhy LS. Association of self-monitoring blood glucose profiles with glycosylated hemoglobin in patients with insulin-dependent diabetes. Methods Enzymol 2000;321:410-7. doi:10.1016/S0076-6879(00)21205-6. 10909069.

26 Skeie S, Kristensen GB, Carlsen S, Sandberg S. Self-monitoring of blood glucose in type 1 diabetes patients with insufficient metabolic control: focused self-monitoring of blood glucose intervention can lower glycated hemoglobin A1C. J Diabetes Sci Technol 2009;3:83-8. doi:10.1177/193229680900300109. 20046652.

27 Wei N, Zheng H, Nathan DM. Empirically establishing blood glucose targets to achieve HbA1c goals. Diabetes Care 2014;37:1048-51. doi:10.2337/dc13-2173. 24513588.

28 Miller KM, Beck RW, Bergenstal RM, et al. T1D Exchange Clinic Network. Evidence of a strong association between frequency of self-monitoring of blood glucose and hemoglobin A1c levels in T1D exchange clinic registry participants. Diabetes Care 2013;36:2009-14. doi:10.2337/dc12-1770. 23378621

29 Service FJ, O'Brien PC. Influence of glycemic variables on hemoglobin A1c. Endocr Pract 2007;13:350-4. doi:10.4158/EP.13.4.350. 17669710.

30 Vervoort G, Goldschmidt HM, van Doorn LG. Nocturnal blood glucose profiles in patients with type 1 diabetes mellitus on multiple $(>$ or $=4$ ) daily insulin injection regimens. Diabet Med 1996:13:794-9. doi:10.1002/(SICI)1096-9136(199609)13:9<794::AID-DIA185>3.0. CO;2-G. 8891454.

31 ISO. ISO 15197:2013. In vitro diagnostic test systems-requirements for blood-glucose monitoring systems for self-testing in managing diabetes mellitus. www.iso.org/iso/home/ store/catalogue_tc/catalogue_detail.htm?csnumber $=54976$.

32 Calle-Pascual AL, Gomez V Leon E, Bordiu E. Foods with a low glycemic index do not improve glycemic control of both type 1 and type 2 diabetic patients after one month of therapy. Diabete Metab 1988;14:629-33.3234586.

33 Laffel LM, Wentzell K, Loughlin C, Tovar A, Moltz K, Brink S. Sick day management using blood 3-hydroxybutyrate (3-OHB) compared with urine ketone monitoring reduces hospital visits in young people with T1DM: a randomized clinical trial. Diabet Med 2006;23:278-84 doi:10.1111/j.1464-5491.2005.01771.x. 16492211.

34 Evert AB, Boucher JL, Cypress $\mathrm{M}$, et al. Nutrition therapy recommendations for the management of adults with diabetes. Diabetes Care 2014;37(Suppl 1):S120-43. doi:10. 2337/dc14-S120. 24357208.

35 Dyson PA, Kelly T, Deakin T, et al. Diabetes UK Nutrition Working Group. Diabetes UK evidence-based nutrition guidelines for the prevention and management of diabetes. Diabet Med 2011;28:1282-8. doi:10.1111/j.1464-5491.2011.03371.x. 21699560.

36 Mann JI, De Leeuw I, Hermansen K, et al. Diabetes and Nutrition Study Group (DNSG) of the European Association. Evidence-based nutritional approaches to the treatment and prevention of diabetes mellitus. Nutr Metab Cardiovasc Dis 2004;14:373-94. doi:10. 1016/S0939-4753(04)80028-0. 15853122.

37 Nutrition SACo. Carbohydrates and Health. 2015. www.govuk/government/uploads/system uploads/attachment data/file/445503/SACN Carbohydrates and Healthpdf.

38 McCulloch DK, Mitchell RD, Ambler J, Tattersall RB. A prospective comparison of 'conventional' and high carbohydrate/high fibre/low fat diets in adults with established type 1 (insulin-dependent) diabetes. Diabetologia 1985;28:208-12. doi:10.1007/ BF00282234. 2991051.

39 Schmidt S, Meldgaard M, Serifovski N, et al. Use of an automated bolus calculator in MDI-treated type 1 diabetes: the BolusCal Study, a randomized controlled pilot study. Diabetes Care 2012;35:984-90. doi:10.2337/dc11-2044. 22344610.

40 Laurenzi A, Bolla AM, Panigoni G, et al. Effects of carbohydrate counting on glucose control and quality of life over 24 weeks in adult patients with type 1 diabetes on continuous subcutaneous insulin infusion: a randomized, prospective clinical trial (GIOCAR). Diabetes Care 2011;34:823-7. doi:10.2337/dc10-1490. 21378215.

41 Scavone G, Manto A, Pitocco D, et al. Effect of carbohydrate counting and medical nutritional therapy on glycaemic control in Type 1 diabetic subjects: a pilot study. Diabet Med 2010:27:477-9. doi:10.1111/j.1464-5491.2010.02963.x. 20536522.

42 Ziegler R, Cavan DA, Cranston I, et al. Use of an insulin bolus advisor improves glycemic control in multiple daily insulin injection (MDI) therapy patients with suboptimal glycemic control: first results from the ABACUS trial. Diabetes Care 2013;36:3613-9. doi:10.2337/ dc13-0251. 23900590

43 Charpentier G, Benhamou PY, Dardari D, et al. TeleDiab Study Group. The Diabeo software enabling individualized insulin dose adjustments combined with telemedicine support improves $\mathrm{HbA1c}$ in poorly controlled type 1 diabetic patients: a 6-month, randomized, open-label, parallel-group, multicenter trial (TeleDiab 1 Study). Diabetes Care 2011;34:533-9. doi:10.2337/dc10-1259. 21266648. 


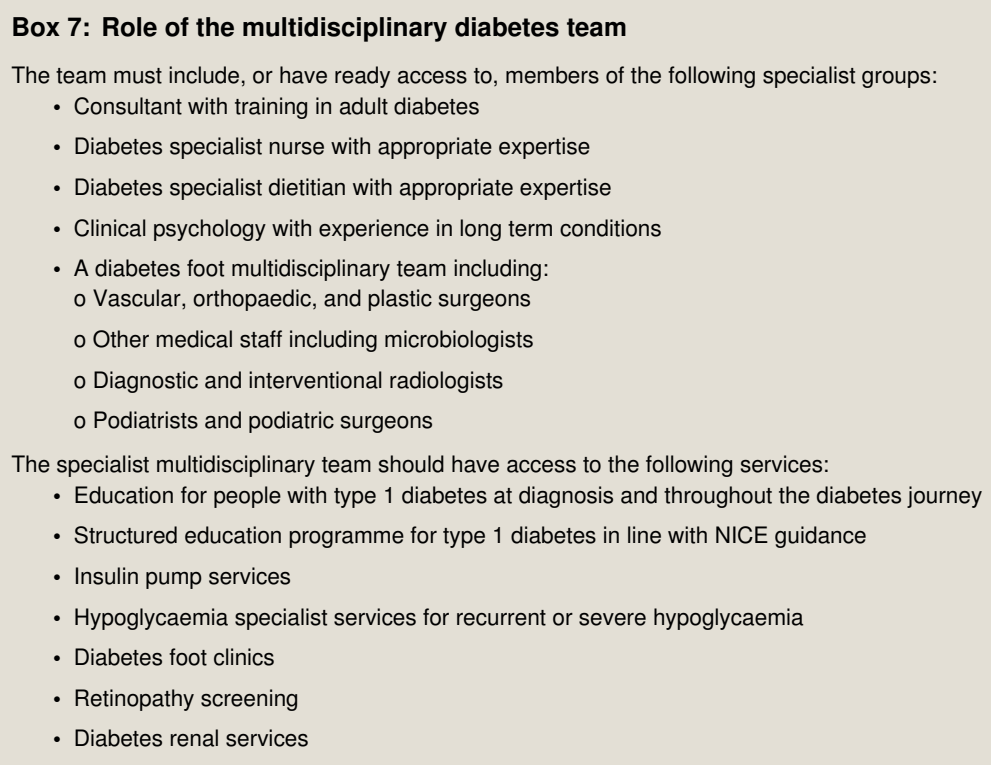

\section{A patient's perspective}

Living with type 1 diabetes can be challenging. Most people only see their clinical team for around an hour a year, so the remaining 8759 hours we manage on our own.

My type 1 diabetes management isn't perfect, but I don't believe anyone's is. It is impossible to list all the factors that go into this, but below are some of the areas I believe enable me to live well with my diabetes.

After receiving little training since diagnosis, I attended a week-long DAFNE course three years ago. I learnt so much. It provided a framework to adapt in different situations and access to the trainers (a diabetes specialist nurse and specialist dietician) after the course ended. It was also the first time I had spoken to another person with type 1 diabetes in the 17 years since my diagnosis. It was life changing and a relief to know I wasn't in this alone. Everyone should have access to ongoing education. Length of diagnosis does not necessarily indicate a person's level of knowledge.

After the course, I kept in contact with the trainers, and this led to my diabetes care moving from my general practice to the diabetes centre at the local hospital. I now have a team around me with specialist knowledge in type 1 diabetes and who are better able to support me. I still see my practice nurse and appreciate her perseverance in more difficult times-never judging me and being supportive, plus persuading me to attend DAFNE. She was one of the first healthcare professionals who seemed to accept I also had a life outside of my type 1 diabetes. I now have a team I trust. I am a member of that team and expect to be an active participant in any discussions.

It is important to have the right tools for the job. This ranges from the right needles and insulin pens right through to insulin pumps and continuous glucose monitoring. I used an insulin pen for many years, but didn't know half-unit pens existed-I am sure this simple change could have helped me. Having a glucose meter I like and enough test strips are a vital part of my care. I now use an insulin pump which gives me more options and flexibility in delivering insulin. Although I wasn't keen when it was first suggested, I now cannot imagine life without it. I also self-fund a continuous glucose monitor. The information and alerts it gives me are invaluable. It has opened my eyes to how my glucose levels react, and motivates me to carry on making adjustments and tweaks which improve my management.

Exercise and type 1 diabetes can be a difficult combination. When I used injections the chaos that exercise caused with blood glucose levels outweighed any benefits for me. Moving to a pump and the flexibility it gave inspired me to give exercise another go. It can still be challenging but attending a sports weekend run by Animas gave me access to so much new information and options. Exercise still effects my blood glucose levels, but I am more aware of what's happening and can take the appropriate action. It inspired me seeing what others were able to achieve. I believe being more active helps me both physically and mentally. I wish there were more specialist help even for un-athletic people like me.

I now recognise type 1 diabetes has a psychological impact as well as a physical one. It is just one part of my everyday life, but it can be unpredictable and is unrelenting. I try to acknowledge the efforts I put in and be more accepting of its changeable nature. The language used around type 1 diabetes also has an effect. Any language used should be non-judgemental. I no longer take a blood glucose "test" that I either pass or fail but rather "check" to see what's happening. A number is neither "good" nor "bad" just above, below, or in range.

The final piece in the puzzle for me is peer support. For many years I didn't know any people with type 1 diabetes, but I am now part of a community both in real life and on-line. I have learnt so much and no longer feel isolated. We are able to support each other, share experiences, and celebrate even the smallest win. It is the difference between knowing the theory and actually living the life.

This list is not all encompassing. It offers a taste of what my life involves, and even after 20 years I am still learning.

\section{Ongoing research questions}

- Can diabetes technologies prevent and resolve impaired hypoglycaemia awareness?

-What methodologies can be used to increase uptake of structured education and to improve their clinical benefit?

- Is there an optimal carbohydrate intake for people with type 1 diabetes?

- How can we incorporate fat and protein content in addition to carbohydrate content in insulin bolus calculations?

- Is peer support effective in improving self management efficacy and confidence in people with type 1 diabetes?

44 Laxminarayan S, Reifman J, Edwards SS, Wolpert H, Steil GM. Bolus estimation-rethinking the effect of meal fat content. Diabetes Technol Ther 2015;17:860-6. doi:10.1089/dia. 2015.0118. 26270134.

45 Thompson PD, Buchner D, Pina IL, et al American Heart Association Council on Clinical Cardiology Subcommittee on Exercise, Rehabilitation, and Prevention American Heart Association Council on Nutrition, Physical Activity, and Metabolism Subcommittee on Physical Activity. Exercise and physical activity in the prevention and treatment of atherosclerotic cardiovascular disease: a statement from the Council on Clinical Cardiology (Subcommittee on Exercise, Rehabilitation, and Prevention) and the Council on Nutrition, Physical Activity, and Metabolism (Subcommittee on Physical Activity). Circulation 2003:107:3109-16. doi:10.1161/01.CIR 0000075572.40158.77.12821592.

46 Galassetti P, Riddell MC. Exercise and type 1 diabetes (T1DM). Compr Physiol 2013;3:1309-36.23897688. 


\section{Continuing medical education resources for healthcare professionals}

NICE guidelines (NG17): Type 1 diabetes in adults: diagnosis and management. www.nice.org.uk/guidance/ng17

DVLA driving regulations (Link: At a glance Section 3. Diabetes Mellitus, page 47). www.gov.uk/government/publications/at-a-glance

ISO standards for glucose meters. www.iso.org/obp/ui/\#iso:std:54976:en

\section{Online resources for self management of type diabetes for patients}

Dose Adjustment For Normal Eating (DAFNE) online resource. www.dafne.uk.com

The Bournemouth e-learning programme. www.bdec-e-learning.com

Diabetes UK. www.diabetes.org.uk/Guide-to-diabetes/Managing-your-diabetes

Guidance on carbohydrate estimation. www.carbsandcals.com

Guidance of exercise. www.excarbs.com

Information of diabetes and sports. www.runsweet.com

\section{Education into practice}

- Do you feel you have the knowledge to recommend structured education to people with type 1 diabetes? How could this be improved?

- How many people with type 1 diabetes in your centre have been referred for structured education? How many attended and completed the course?

-What options are there for ongoing education and refresher courses in your area?

\section{How patients were involved in this article}

Author Philippa Cooper has lived with type 1 diabetes for 20 years. Her experience has informed the structure and content of the review, and she has provided a patient's perspective box.

47 Sovik O, Thordarson H. Dead-in-bed syndrome in young diabetic patients. Diabetes Care 1999:22(Suppl 2):B40-2.10097898.

48 McTavish L, Krebs JD, Weatherall M, Wiltshire E. Weight-based hypoglycaemia treatmen protocol for adults with type 1 diabetes: a randomized crossover clinical trial. Diabet Med 2015;32:1143-8. doi:10.1111/dme.12730. 25683747.

49 Dagogo-Jack SE, Craft S, Cryer PE. Hypoglycemia-associated autonomic failure in insulin-dependent diabetes mellitus. Recent antecedent hypoglycemia reduces autonomic responses to, symptoms of, and defense against subsequent hypoglycemia. J Clin Invest 1993:91:819-28. doi:10.1172/JCl116302. 8450063.

50 Heller SR, Cryer PE. Reduced neuroendocrine and symptomatic responses to subsequen hypoglycemia after 1 episode of hypoglycemia in nondiabetic humans. Diabetes 1991;40:223-6. doi:10.2337/diab.40.2.223. 1991573.

51 Gold AE, MacLeod KM, Frier BM. Frequency of severe hypoglycemia in patients with type I diabetes with impaired awareness of hypoglycemia. Diabetes Care 1994:17:697-703. doi:10.2337/diacare.17.7.697. 7924780

52 Clarke WL, Cox DJ, Gonder-Frederick LA, Julian D, Schlundt D, Polonsky W. Reduced awareness of hypoglycemia in adults with IDDM. A prospective study of hypoglycemic frequency and associated symptoms. Diabetes Care 1995;18:517-22. doi:10.2337/diacare. 18.4.517. 7497862 .

53 Lawton J, Rankin D, Elliott J, et al. U.K. NIHR DAFNE Study Group. Experiences, views, and support needs of family members of people with hypoglycemia unawareness: interview study. Diabetes Care 2014;37:109-15. doi:10.2337/dc13-1154. 23990515.

54 Snow R, Humphrey C, Sandall J. What happens when patients know more than their doctors? Experiences of health interactions after diabetes patient education: a qualitative patient-led study. BMJ Open 2013;3:e003583. doi:10.1136/bmjopen-2013patient-led study. BM

55 Anderson RJ, Freedland KE, Clouse RE, Lustman PJ. The prevalence of comorbid depression in adults with diabetes: a meta-analysis. Diabetes Care 2001;24:1069-78. doi:10.2337/diacare.24.6.1069. 11375373.

Published by the BMJ Publishing Group Limited. For permission to use (where not already granted under a licence) please go to http://group.bmj.com/group/rights-licensing/ permissions 